\title{
Bacteriological and Pathological Investigation of Nasal Passage Infections of Chickens (Gallus gallus)
}

\author{
M. S. Hossain, S. Akter, M. Ali, P. M. Das and M. M. Hossain* \\ Department of Pathology, Faculty of Veterinary Science, Bangladesh Agricultural University, \\ Mymensingh-2202, Bangladesh \\ *Corresponding author and Email: mmhossain04@yahoo.com.au
}

Received: 20 May $2012 \quad$ Accepted: 18 May 2013

\begin{abstract}
An experiment was conducted at the Bangladesh Agricultural University, Mymensingh during July 2011 to May 2012 to investigate the prevalence of bacteria as well as pathological lesions in the nasal passages of dead chickens. Thirty nasal passage swabs from 30 dead birds (20 from SK Veterinary Diagnostic Centre (SKVDC) and 10 from the Department of Pathology, BAU were collected in sterile nutrient broth. The histopathological samples $(n=6)$ were collected in $10 \%$ neutral buffered formalin. The isolation and identification of bacteria were performed by culturing in different media, staining and biochemical tests. The collected tissues were fixed, processed, sectioned, stained and studied with light microscope. The prevalence of bacteria 30.43\% Escherichia coli, $47.83 \%$ Staphylococcus sp., $13.04 \%$ Pasteurella sp., and $8.69 \%$ Klebsiella sp. were found in nasal passages $(\mathrm{n}=30)$ of dead chickens. Two cases of mixed infection with E. coli and Pasteurella isolates, and one case with Klebsiella and E. coli isolates were identified. Six tissue samples of grossly identifiable lesions such as congested and mucus filled nasal passages from 6 dead chickens were processed for histopathology. Microscopically, the section of nasal passages in general showed congested mucosa with excessive infiltration of heterophils and lymphocytes. The lining epithelia of nasal passage revealed acanthosis, hyperkeratosis and disruption of nasal epithelia. There was also hyperplasia of different mucous glands of nasal passages. Klebsiella sp. affected nasal tissues showed comparatively severe lesions than that of other bacterial infection in chickens.
\end{abstract}

\section{Keywords: Bacteria, pathology, rhinitis, chickens}

\section{Introduction}

Diseases of the respiratory tract have an important role in poultry. Among the systemic diseases, respiratory system diseases generally ranked first (Glisson, 1998). A mixed infection is well known as a causative agent of chronic respiratory diseases in chickens (Nunoya et al., 1999). These diseases may emerge as the reflection of either primary or a multisystem diseases. In the etiology of respiratory system diseases, bacteria, virus, parasite, fungi, nutrition and environmental factors are effective (Glisson, 1998).

In avian host, several microorganisms of the genus Pasteurella (P. multocida, P. gallinarum, $P$. haemolylica and $P$. anatipestifer), Bordetela (B. avium) and Avibacterium (A. paragallinarum) are involved in respiratory disease complex (Hafez, 2002). E. coli associated with respiratory infection in chickens have also been reported (Sukhon et al., 2002). Ornithobacterium rhinotracheale has recently 
been identified as a pathogen causing respiratory tract infections in poultry and other birds (Chin et al., 2003). Concurrent infection of young poultry with Klebsiella pneumonia increased the severity of respiratory diseases (Saif et al., 2003). Weakness, gasping, pump handled respiration, dyspnoea, mucous discharge and increased mortality, swelling of sinuses, facial oedema, tracheitis, exudative pneumonia, pleuritis, air sacculitis, pericarditis, sinusitis, drop in egg production, poor egg quality characterize the infection.

Recent investigation (Popy et al., 2011) in Bangladesh showed that the prevalence of bacteria $6.03 \% \quad$ Klebsiella sp., $38.79 \%$ Escherichia coli., $8.26 \%$ Pasteurella sp., $5.17 \%$ Bacillus sp., and $41.37 \%$ Staphylococcus sp., were present in both trachea $(n=50)$ and nasal sinuses $(n=50)$ of dead chickens. Thus, it is revealed that the bacteria of nasal passages of chickens cause a great loss to the farmers. So, the present investigation has been undertaken to enrich the knowledge of stockholders with a view (a) to isolate, identify and detect the prevalence of the bacteria from nasal passage of chickens and (b) to determine the pathological lesions in nasal passage. The identified bacteria from nasal passage of chickens and pathological lesions will enrich the knowledge of veterinarian for the diagnosis of rhinitis and their treatment.

\section{Materials and Methods}

\subsection{Samples}

A total of 30 nasal swabs from layer birds of average age 6 months, of which 20 swabs from SKVDC, Durgabari Road, Mymensingh, and 10 swabs from Department of Pathology, BAU, were collected for the isolation of bacteria. Six tissue samples grossly, identifiable lesions such as congested and inflamed nasal passages of four from SKVDC, and two from Department of Pathology, BAU, were collected in $10 \%$ buffered formalin for histopathology. The study was conducted during July 2011 to May 2012.

\subsection{Bacteriological media and reagents}

Nutrient agar (NA), Blood agar (BA), MacConkey agar (McA) (Techno Pharm., India), Eosin methylene blue agar (Oxoid, England), Nutrient broth (HiMedia Lab. Pvt., India) were used in this study.

\section{3. Different sugars}

Dextrose (LOBA, India), Sucrose (Wako, Japan), Lactose (Merc, England), Maltose (Techno Phann., India), Dulcitol (Difco, USA), Xylose (Riedel-ae Hain, USA), Mannitol (Beximco. PHaema, Germany) and Inositol (LOBA, India) were used in this study.

\section{4. Primary isolation of organisms}

From the nutrient broth, 30 swab samples were placed in nutrient agar plate and incubated for overnight at $37^{\circ} \mathrm{C}$ for the growth of the organisms following routine procedures.

\section{5. Subculture in selective culture media}

All the 30 samples were sub-cultured in NA, McA and EMB agar. Blood agar media was used only for Pasteurella sp. and Staphylococcus sp. A small amount of inoculums from the nutrient agar was spread into different culture media and incubated at $37^{\circ} \mathrm{C}$ for overnight. The identification of the organisms was carried out by the different colony morphology, staining characteristics and biochemical tests as described by Naowarat (2007), Deena and Adriana (2005) and Brooks et al. (2002). On the basis of colony morphology, staining and biochemical characteristics, the organisms were isolated and identified. From the colony morphology the bacteria were categorized into different groups. From each group, representative samples were tested for biochemical test for the confirmation of the isolates.

\section{6. Staining}

Morphological characterization of the bacterial isolates by Gram's staining and Leishman's staining methods were used in this study (Brooks et al., 2002). 


\section{7. Carbohydrate fermentation test procedure}

Five basic sugars such as dextrose, sucrose, lactose, maltose and mannitol were used to determine the fermentation properties of the organisms. Three samples of tentatively diagnosed E. coli, 3 samples of tentatively diagnosed Pasteurella sp. and 2 samples of tentatively diagnosed Klebsiella sp. were used for carbohydrate fermentation test. The test was performed by inoculating $5 \mathrm{ml}$ of nutrient broth culture of the organisms into the test tubes containing different sugar media and incubated for 72 hours at $37^{\circ} \mathrm{C}$. Acid production was indicated by the color change from red to yellow of the medium and the gas production was noted by the appearance of the gas bubbles in the inverted Durham's tube (Mishra et al., 2002; Prasad et al.,1997; Chowdhury et al., 1985).

\section{8. Voges-Proskauer, MR - VP, Indole and Catalase tests}

To confirm the bacteria, above tests were performed as described by Mishra et al. (2002).

\section{9. Gross Pathology}

The postmortem examination was carried out carefully on dead chickens. Gross tissue changes such as congested nasal passages filled with mucus were observed and recorded carefully and representative samples containing lesions were fixed in $10 \%$ neutral buffered formalin for histopathological examination.

\subsection{Histopathology}

Six nasal passage tissues were selected as representative samples from six dead birds for histopathlogical study. The formalin fixed tissues were trimmed, processed, sectioned and stained following standard procedure (Luna, 1968).

\section{11. Photomicrography}

Photomicrography was taken at the Department of Pathology using photomicrographic camera (Olympus PM-C 35 Model) onto fitted with Olympus microscope (Olympus, Japan).

\section{Results and Discussion}

By subculturing of 30 swabs from nasal passages, 23 isolates of bacteria were identified. On the basis of colony characters, staining characters, sugar fermentation and biochemical properties, the isolates were categorized into 4 types of bacteria (Table 1). They were E. coli (7), and Staphylococcus sp. (11), Pasteurella sp. (3), Klebsiella sp. (2). Two mixed infection of E. coli and Pasteurella isolates from two samples, and one mixed infection of Klebsiella and $E$. coli from one sample were identified.

\subsection{Colony characters, staining characters, biochemical tests and enzymatic activity test for E. coli.}

Thirty swab samples from nasal passages were subcultured on EMB agar and MacConkey agar for isolation of E. coli. Among them 7 were positive for $E$. coli.. In positive cases, all $7 E$. coli produced smooth circular colonies with dark centers and metallic sheen on EMB agar (Fig. 1). The prevalence of Escherichia coli in nasal passage swabs of dead chickens was $30.43 \%$ (7 E. coli in 23 isolates from 30 nasal passage swabs), which is lower than those reported by Murthy et al. (2008) and higher than those of Trkyilmaz (2005) and Ibrahim et al. (2004). In this study, prevalence of $E$. coli was less which might be due to age and breeds of the chickens and in some cases, prevalence of $E$. coli were higher which might be due to poor management. The colony characters of all isolated $E$. coli were the production of metallic sheen on EMB agar media and rose pink colored colony on the MacConkey agar media which corresponded with the findings of Sharada et al. (1999). E. coli was gram negative short rod, varying from coccoid shape to long filamentous (Fig. 2). All isolated $E$. coli in this investigation were MR and indole positive, and VP negative. Similar results were reported by Mishra et al. (2002). 
Table 1. Identification of bacteria isolated from nasal passages of chickens

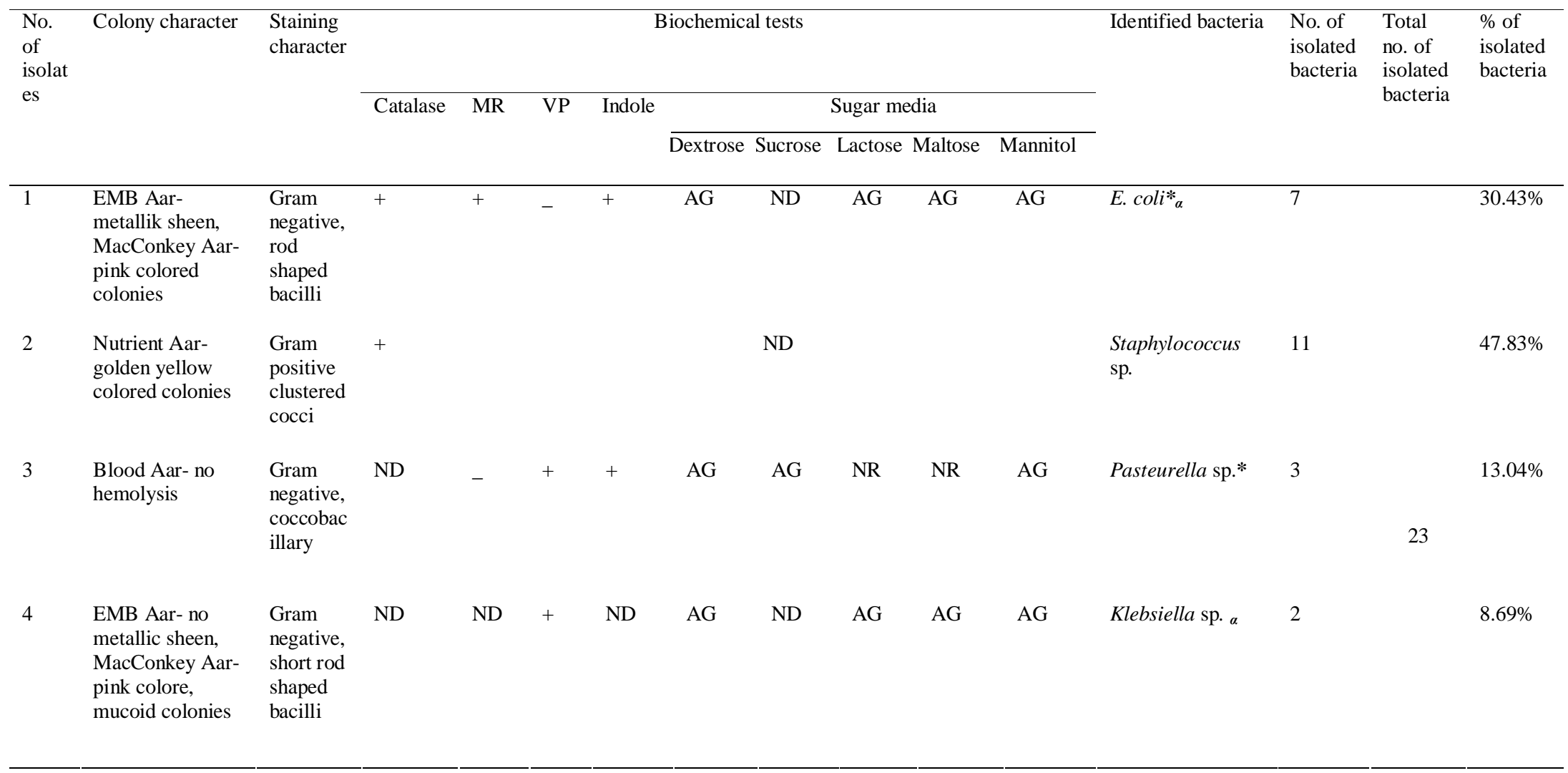

$\mathrm{MR}=$ Methyl Red, VP= Voges-Proskauer, AG= Acid and Gas, $+=$ =Positive, $-=$ Negative, ND=Not done, NR=No reaction

*= Mixed infection of E. coli and Pasteurella sp. from 2 cases

$\alpha=$ Mixed infection of Klebsiella and E. coli from 1 case 


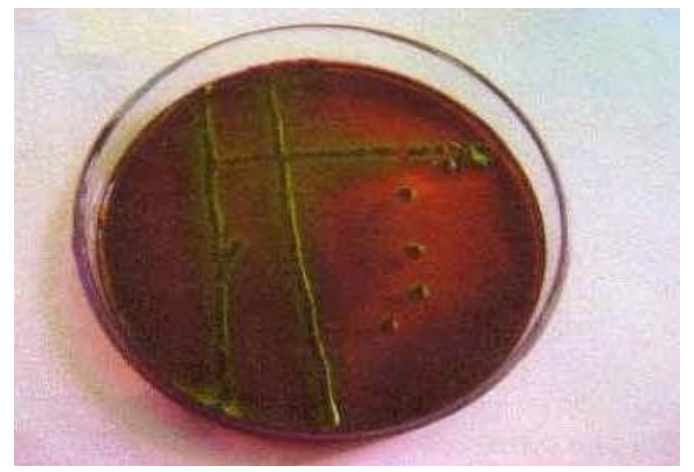

Fig.1. E. coli showing greenish colored colony with metallic sheen on EMB agar

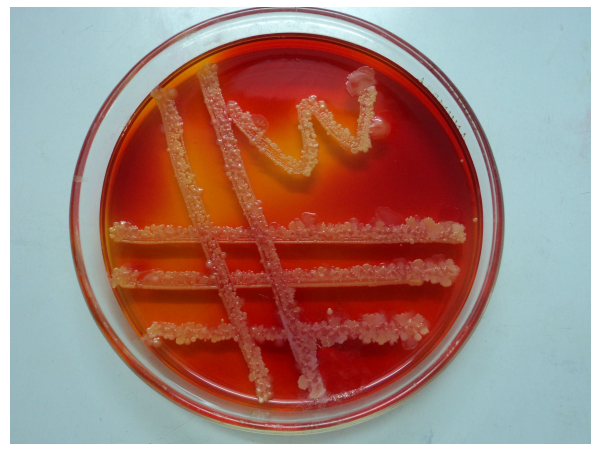

Fig.3. Staphylococcus sp. produces yellow color colony on mannitol salt agar

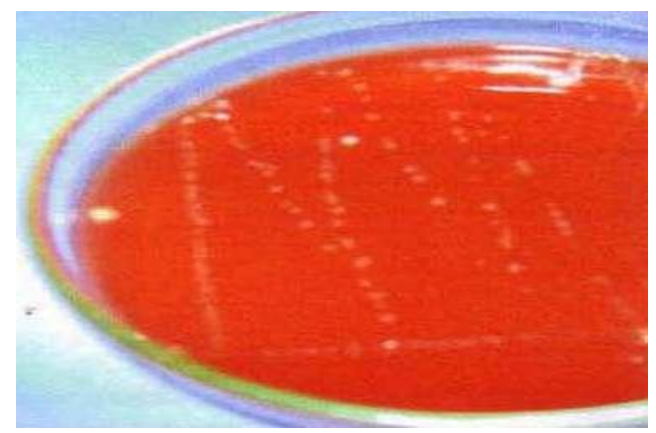

Fig.5. Pasteurella sp.showing white, dull colony and no hemolysis on blood agar

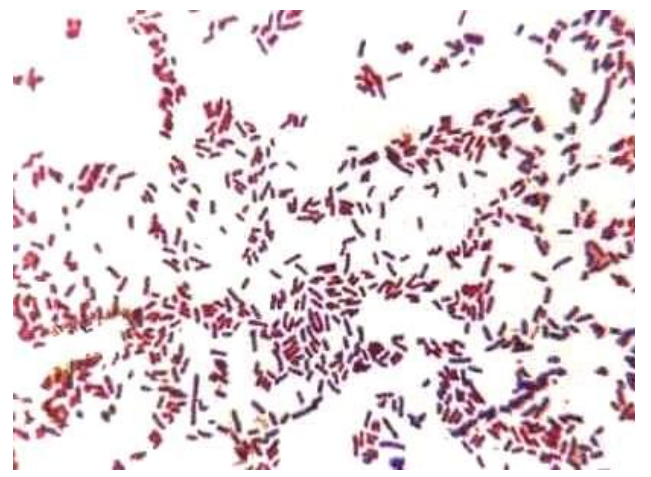

Fig.2. E. coli in grams staining showing gram negative, short rod-shaped organism

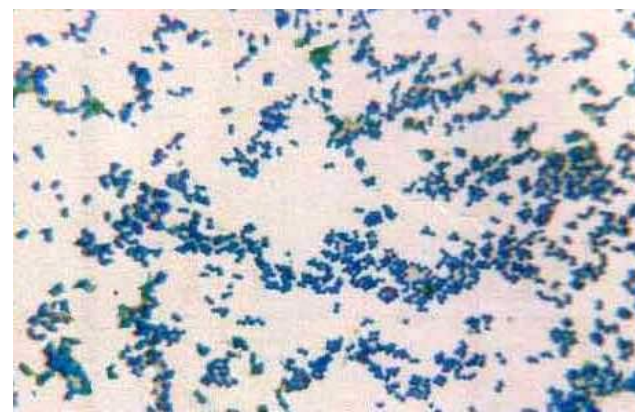

Fig.4. Staphylococcus sp. showing gram positive, cocci and arrranged in grape like clusters (Modified grams staining $\times 830$ )

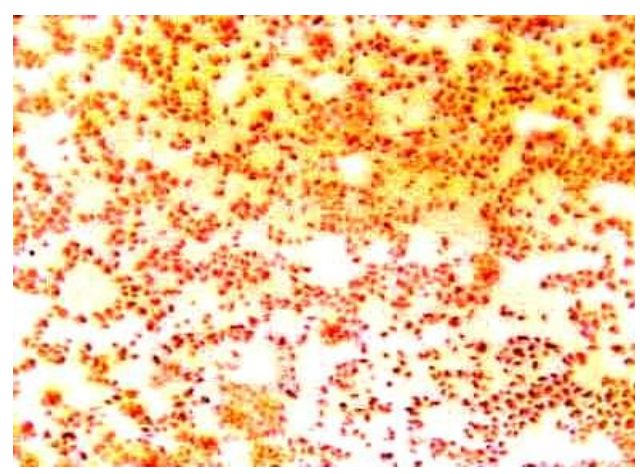

Fig. 6. Pasteurella sp.showing graw negative and coccobacillary shaped organism with bipoar appeareance 


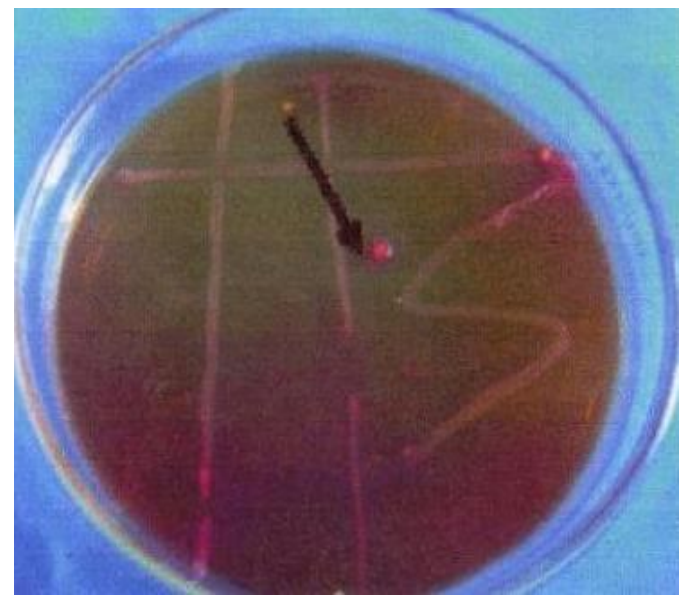

Fig.7. Pink colored mucoid colony produced by Klebsiella sp. on MacConkey agar

\subsection{Colony characters, staining characters, and enzymatic activity tests of Staphylococcus sp.}

In the present study $47.83 \%$ Staphylococcus sp. (Fig. 3) were found (11 Staphylococcus sp. in 23 isolates from 30 nasal passage swabs) in the nasal passages of dead chickens. These findings were lower than those reported by Trkyilmaz (2005). The colonies of all isolates of Staphylococcus sp. on nutrient agar plate were golden yellow in color, they were gram-positive cocci arranged in a pairs or grape like clusters (Fig. 4) and catalase test positive which were reported by Brooks et al. (2002).

\subsection{Colony characters, staining characters, biochemical tests and enzymatic activity test for Pasturella sp.}

The prevalence of Pasteurella sp. (Fig. 5) was $13.04 \%$ (3 Pasteurella sp. in 23 isolates from 30 nasal passage swabs) which was lower than the values reported by other authors (Murthy et al., 2008; Trkyilmaz, 2005). In this study the prevalence of Pasteurella sp. was less which might be due to age and breeds of the chickens

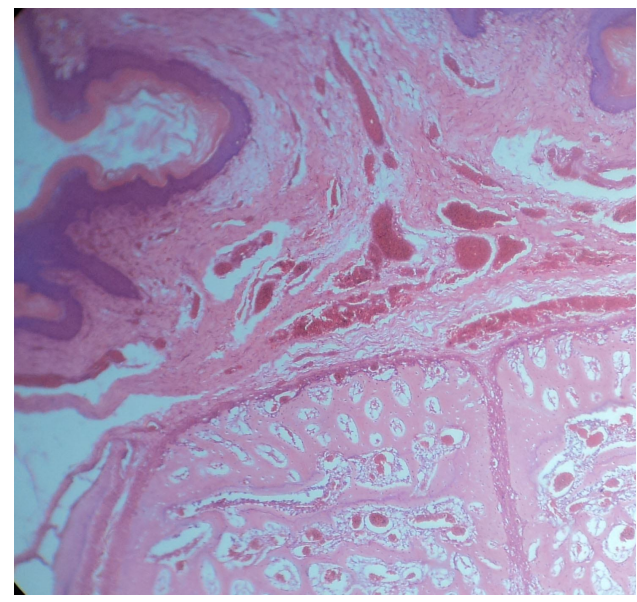

Fig. 8. The section of nasal passage showing acanthosis, mucous/parakeratosis, congestion of blood vessels and accumulation of inflammatory cells in case of Pasteurella sp. affected chicken. (H \& E stain, ×333)

and also for the resistant power of the commercial chickens due to proper management, vaccination and nutrition. Whitish, opaque circular, translucent and non-hemolytic colonies on blood agar media produced by Pasteurella sp. isolates of present study which were similar to the findings of Chowdhury et al. (1985). In this study the staining characters of isolated Pasteurella sp. were coccobacillary, bipolar organisms in Leishman's staining (Fig. 6) and fermentation reaction of Pasteurella sp. with dextrose, sucrose and mannitol with production of acid only and no reaction occurred in lactose and maltose which were similar to the other authors (Prasad et al.,1997; Chowdhury et al., 1985).

\subsection{Colony characters, staining characters and biochemical tests for Klebsiella sp.}

The prevalence of Klebsiella sp. (Fig. 7) was $8.69 \%$ ( 2 Klebsiella sp. in 23 isolates from 30 nasal passage swabs) in the present study which was higher than the values reported by Popy et al. (2011) in Bangladesh. In that study the prevalence of Klebsiella sp. was less which 
might be due to age and breeds of the chickens, geographic variation and also for the resistant power of the commercial chickens due to proper management, vaccination and nutrition. Klebsiella sp. isolates of this study produced pink colored mucoid colony on MacConkey agar, which was similar to the report of other author (Naowarat, 2007). The staining characters of isolated Klebsiella sp. were gram negative, thick rod shaped bacilli which corresponds with Deena and Adriana's (2005) findings. All Klebsiella sp. produced acid and gas in lactose, dextrose, maltose and mannitol. The organisms were Voges-Proskauer positive, methyl red negative and catalase positive which were also similar to the results of other authors (Naowarat, 2007; Deena and Adriana, 2005).

\subsection{Colony characters of detected mixed infection}

Two representative samples out of 30 were identified as mixed infection. One mixed infection comprised of E. coli and Pasteurella sp. while other mixed infection comprised of Klebsiella and E. coli. The colony characters, staining features and response to different biochemical and sugar fermentation tests of Pasteurella sp., E. coli and Klebsiella had already been discussed in previous section.

\section{6. Gross pathology}

Six tissue samples out of 30 cases showed gross lesions of nasal passage characterized by congested, hemorrhagic and mucous filled nasal passage, and erosion of passage tissue etc. Very similar findings were reported by many investigators (Esquinas and Iregui, 2007; Moustafa, 2005; Jaswinder et al., 2005).

\section{7. Histopathology}

Histopathologically, no striking differences were found in tissues of nasal passage, though four types of bacteria were identified. The section of the nasal passages in general showed congested mucosa with excessive infiltration of inflammatory cells (Fig. 8). The lining epithelia of nasal passage revealed acanthosis, hyperkeratosis and disruption of nasal epithelia. There was also hyperplasia of different mucous glands of nasal passages. However, on the basis of severity of lesions it seemed that Klebsiella sp. affected nasal tissues of chickens were severe than other bacteria affected nasal tissues of chickens. Almost same lesions of rhinitis caused by different bacteria were reported by many investigators (Esquinas and Iregui, 2007; Moustafa, 2005; Jaswinder et al., 2005).

In this study, the bacteria isolated from the nasal passages were E. coli, Pasteurella sp., Klebsiella sp. and Staphylococcus sp. E. coli can cause different diseases in poultry including respiratory infection such as swollen head syndrome, respiratory rales, severe nasal discharge; Pasteurella sp is the etiological agent of fowl cholera and it also induces pneumonia, chronic rhinitis, facial edema; Klebsiella sp., E. coli. and Pasteurella sp. combinedly cause pneumonia and tracheitis reported by several authors (Fuad and Mohammad, 2008; Moursi and Sabah, 2008; Drago and Don, 1996). However, in the present investigation, different kinds of lesions other than rhinitis were not found.

\section{Conclusions}

The recorded lesions of nasal passages of chicken in the present investigation were rhinitis. The prevalence of bacteria $30.43 \%$ E. coli, $47.83 \%$ Staphylococcus sp., $13.04 \%$, Pasteurella sp., and $8.69 \%$ Klebsiella sp., were found in nasal passages of dead chickens. Two cases of mixed infection of $E$. coli and Pasteurella isolates, and one case of mixed infection with Klebsiella and E. coli isolates were identified. Grossly identifiable lesions such as congestion and mucus filled nasal passages were found. Microscopically, the section of the nasal passages in general showed congestion with excessive infiltration of heterophils and lymphocytes. The lining epithelia of nasal passage revealed acanthosis, hyperkeratosis and disruption of nasal epithelia. There was also hyperplasia of different mucous glands of nasal 
passages. Klebsiella sp. affected nasal tissues showed comparatively severe lesions than other bacteria affected nasal tissues of chickens. The identified bacteria from nasal passage of chickens and pathological lesions will enrich the knowledge of veterinarian for the diagnosis of rhinitis and their treatment.

\section{References}

Brooks, G. F., Butel, J. S. and Morse, S. A. 2002. Jawetz, Melnick and Adelberg's Medical Microbiology. 22th edn. MacGraw Hill, New Delhi, India, 197-202 pp.

Chin, R. P., Empel, V. P. C. M. and Hafez, H. M. 2003. Ornithobocterium rhinotracheale infection, In: Disease of Poultry. $11^{\text {th }}$ edn. Saif, Y. M., Barnes, H. J., Olisson, J. R., Fadly, A. M., McDougald, L. R., Swayne, D. E. (cds.). Iowa state University Press, Ames, Iowa, 683-690 pp.

Chowdhury, R. A., Amin, N. M., Rahman, A. and Ali, M. R. 1985. Investigation of natural outbreak of fowl cholera. Bangladesh Veterinary Journal, 19:49-56.

Deena J. and Adriana L. Y. 2005 Gram stain: Gram-negative rod, microbes. American Society for Microbiology. http/www.microbelibrary.org.

Drago, C. J. I. and Don A. F. 1996. Bacterial diseases of respiratory tract, In: Poultry Diseases and Meat Hygiene: A Color Atlas. $1^{\text {st }}$ edn. Iowa state University Press, Ames, Iowa, 250-290 pp.

Esquinas, C. P. and Iregui. C. C. 2007. Mechanisms of bacterial pathogenesis in respiratory processes: pasteurellosis. International Journal of Poultry Science, 75(12): 21-32.

Fouad, I. A. and Mohammed, H. A. A. E. 2008. Bacteriological and pathological studies on Pasteurella haemolytica in ducks in
Assiut. governorate. Assiut Veterinary Medicine Journal, 54 (116): 220-230.

Glisson, J. R. 1998. Bacterial respiratory diseases of poultry. Poultry Science, 77 (8):1139-1142.

Hafez, M. H. 2002. Diagnosis of Ornithobacterium rhinotracheale. International Journal of Poultry Science, 1:114-118.

Ibrahim, R. S., Mousa. Aly, M. and Abdel Naser, W. E. 2004. Complicated infectious coryza in broiler and layer chickens in Egypt. Assiut Veterinary Medicine Journal, 50/(103): 90-130.

Jaswinder, K., Banga, H. S., Sood, N. K., Kuldip G. and Amarjit, S. 2005. Pathological studies on naturally occurring infectious coryza in chickens. Indian Animal Science Journal, 75 (2): 209-211.

Luna, L.G. 1968. Manual of histologic staining methods of the Armed Forces Institute of Pathology. 3rd ed. McGraw-Hill, New York.

Mishra, A., Shardr, F., Chhabrao D. and Moghe, M. N. 2002. E. coli isolated from domestic poultry farm. Indian Journal of Animal Science, 72:727-729.

Moursi, M. K. and Sabah, K. H., 2008. Studies on chickens ornithobacterium sp. infection at Ismailia province. Assiut Veterinary Medicine Journal, 54 (117):357-372.

Moustafa, F. A. M. 2005. Some studies on bacterial causes associated with cases of swollen head syndrome in chickens. Assiut Veterinary Medicine Journal, 51(84): 90-105

Murthy, T. R. G. K., Dorairajatr, N., Gurusamypalayam, A. B., Dinakaran, A. M. and Saravanaba, K. 2008. Pathogenic bacteria related to respiratory diseases in poultry with reference to Ornithobacterium rhinotracheale isolated 
in India. Indian Animal Science Journal, 78 (2): 131-140.

Naowarat C. 2007. Eosin-Methylene Blue. American Society for Microbiology. http ://www.microbelibrary. org.

Nunoya, T. T., Yagihashi, M., Tarima. and Nagasawa, Y. 1999. Occurance of keratoconjuntivitis app:arently caused by Mycoplasma gallisrpticum in layer chickens. Veterinary Pathology, 32:11-18.

Popy, N., Asaduzzaman, M., Mia, M. S., Siddika, A., Sufian, M. A. and Hossain, M. M. 2011. Pathological study on the upper respiratory tract infection of chickens and isolation and identification of causal bacteria. Bangladesh Veterinarian, 28 (2):60-69

Prasad, V., Murthy. K. K. and Rao, T. V. J. 1997. In vitro antibiogram studies of $E$. coli in chickens. Indian Veterinary Journal, 76 (7):616-617.
Saif, Y. M., Barnes, H .J., Glisson, J. R., Fadly, A. M., McDougald, L.R. and Swayne, D. E. 2003. Diseases of poultry. $11^{\text {th }}$ edn. Iowa state universitl' press. Blackwell publishing company, $849 \mathrm{p}$.

Sharada, R., Krishnappa, G., Raghavan, R. and Sreevinas, G. A. 1999. Isolation and serotyping of $E$. coli from different conditions in poultry. Indian Journal of Poultry Science, 34 (3):366-369.

Sukhon, E. S. N., Musa, A. and Attar, M. A. 2002. Studies on the bacterial etiology of airsacculitis of broilers in Northem and Middle Jordan with special reference to Escherichia coli, ornithobacterium rhinotracheale and Bordetella avium. Avian Disease, 46: 605-612

Trkyilmaz, S. 2005. Isolation and serotyping of ornithobacterium rhinotracheale from Poultry. Turkish Journal of Veterinary and Animal Sciences, 29:1299-1304. 